\title{
Prevalence of comorbidities in obstructive sleep apnea patients in comparison with general population
}

\author{
Asmath Qureshi', Nandan Putti', Latha Sarma², Vivek V. Byahatti ${ }^{3}$ \\ 1 Doctor of Pharmacy, Krishna Institute of Medical Sciences, Begumpet, Secunderabad, Telangana \\ 500003 , India. \\ 2 Consultant Pulmonologist, Critical Respiratory andSleep Specialist, Department of Pulmonology, Krishna \\ Institute of Medical Sciences, Begumpet, Secunderabad, Telangana 500003, India. \\ ${ }^{3}$ Professor and HoD of Pharmacognosy, Bharat Institute of Technology, Ibrahimpatanam, Hyderabad, \\ Telangana 501510, India.
}

DOI No:10.5958/0974-0155.2015.00016.9

Indian J Sleep Med 2015; 10.3, 105-110

\begin{abstract}
Background: Obstructive sleep apnea (OSA) is a breathing disorder that occurs in sleep, which poses many threats more than disturbed sleep. It is associated with major comorbidities. There are insufficient studies in India regarding multiple comorbidities and OSA syndrome. The objective of this studyis to compare the incidence of comorbidities in documented OSA patients with subjects without OSA.

Methods: The study was carried out with a total of 274 patients in tertiary-care hospital for a period of 6 months. The study design used was retrospective case-control study. Patient history was taken from the documented records. SPSS package was used for estimating results.

Results: Mean age of patients was $55.53 \pm 11.37$ years. Average apnea-hypopnea index was $45.50 \pm 24.51$. A total of 110 men and 27 women were seen. The age group of 45-65 years recorded the highest number of OSA patients with a greater severity. The prevalence of hypertension (HT) in case group was $38.4 \%$. When the correlation coefficient was calculated, HT correlated the most with OSA $(r=0.513, P=0.01)$ followed by stroke, hypothyroidism, and coronary artery disease. The least correlation was withdiabetes mellitus $(r=0.172$, $P=0.01$ ) withprevalence of $40.15 \%$ in case group.

Conclusions: The study showed that prevalence of comorbidities is more in patients with OSA than without OSA.
\end{abstract}

Keywords: OSA,comorbidities, apnea hypopnea index, case-control study, odds ratio, hypertension.

Address for correspondence

\section{Asmath Qureshi}

Doctor of Pharmacy

Krishna Institute of Medical Sciences

1-8-31/1, Minister Road, Krishna Nagar Colony

Begumpet, Secunderabad

Telangana 500003, India

Email:asmathqureshi@gmail.com

\section{Introduction}

The incidence of obstructive sleep apnea (OSA) is increasing in India. The derangements caused by recurrent failure of the upper airway are directly related to the signs and symptoms and consequences of OSA, which include sleep fragmentation, hypoxia, hypercapnia, notice able 
variations in intrathoracic pressure, and enhanced sympathetic activity.

OSA is a recognized risk factor for systemic hypertension ${ }^{1}$. OSA is generally related tonighttime hypertension and toa reversed 24-hour arterial pressure profile ${ }^{2}$. Enhanced after load at the time of obstructive happening, nighttime hypoxemia, and subsequent increased sympathoadrenal activity damageleft ventricular function ${ }^{3}$.

It is well known that causes a worst scenario of insulin resistance, leading toobvious compensatory hyperinsulinemia and, thereby, elevating the necessity for overdoses of exogenous insulin ${ }^{4}$. Thedamage in glucose tolerance is associated with oxygen desaturation. A $4 \%$ reductionin saturation results in the associated odds ratio for deteriorating glucose tolerance of $1.99^{5}$.

Severe OSA is associated with an increased incidence of coronary vascular disease independent of insulin resistance and obesity. OSA is also associated with increased risk of stroke and other cardiovascular diseases, with mechanisms being increased sympathetic activity, endothelial dysfunction, elevated fibrinogen levels, increasedin vivo platelet activation during sleep, alteration of in vitro platelet agreeability, hypercoagulability, and decreased cerebral blood flow in sleep apnea patients ${ }^{6}$.

The mechanisms suggestive of clarifying how hypothyroidism results in OSA comprise mucoprotein deposition in the upper airway, reduced neural output to the upper airway musculature, obesity, and aberrations in ventilatory control ${ }^{7}$.

Most of the people are undiagnosed, especially malesubjects. There are insufficient studies in India regarding multiple comorbidities and OSA syndrome. All the studies have focused on a single comorbid condition. This study aims at including five comorbid conditions and to determine which among these carries the most significant correlation with OSA.

\section{Material and Methods}

A retrospective case-control observational study was carried out in Department of Pulmonology of a 1000bedded tertiary-care hospital. This study was conducted for 6 months after taking permission from Institutional Ethics Committee.
The type of sleep study performed was split-night or whole-night polysomnography (PSG), with 55-channel ALICE-5 PSG system. Enrolment of the patient was from the Outpatient Department of Pulmonology. Patients who were diagnosed as OSA in whole-or split-night polysomnography were included in case group, whereas patients whose sleep study was negative for OSA were included in control group.

The information regarding comorbidities, body mass index (BMI), other baseline data, andapnea-hypopnea index (AHI)value was collected from the patient's medical records and polysomnography reports.

With estimated proportion of incidence of OSA being $14 \%$, confidence interval $(\mathrm{CI})$ of $95 \%$, power of $85 \%$, sample size was calculated as 137 in case group and 137 in control group. A total of 274 patients were involved in the study.

The severity of OSA is based on AHI: mild, 5-14; moderate, 15-29; and severe e"30.

Clinically, OSA is defined by the incidenceof daytime sleepiness, loud snoring, observed breathing interludes or arousals owing to gasping or choking in the presence of at least fiveobstructive respiratory events (apneas, hypopneas, or respiratory efforts-related arousals) per hour of sleep ${ }^{8}$.

\section{Selection Criteria for Case Group}

Following were the criteria for inclusion in the study.

- Patients diagnosed as mild, moderate, or severe OSA by either whole-night or split-night polysomnography.

- Patients from age group of 18 to 80 years.

\section{Exclusion Criteria}

- Pregnant women.

- Inconclusive sleep study.

\section{Selection Criteria for Control Group}

\section{Inclusion Criteria}

- Control group is selected so as to match the case in terms of age and sex.

- Subjects must not have OSA. 


\section{Tools Used}

- Data collection form (patient history) designed for OSA patient.

- Data entry was done in Microsoft Excel.

- SPSS package was used for estimating results.

\section{Statistical Analysis}

Odds ratio was calculated to estimate the level of comorbidities in case and control groups. Correlation coefficient was estimated for different comorbidities and OSA. $P$ value of d" 0.05 was considered as statistically significant.

\section{Results}

After retrieving all the data and analyzing, the descriptive statistics of the study population was calculated.

The total number of male and female patients in the case group was 110 and 27 , respectively. The same number of subjects was taken in controlgroup. The mean age of population without OSA was close to population withOSA, indicating thatboth the groups were matched in terms of age and gender.

The age group of 45-65 years recorded the highest number of OSA patients in both male and female population: 60 and 19 patients respectively. The 25-35 years age group and 75-86 years age group recorded least number of patients in both the genders. The detailed information is provided in (Table 1).

Table 1: Age- and gender-wise categorization of the study population

\begin{tabular}{|l|l|l|l|l|c|c|}
\hline $\begin{array}{l}\text { Age } \\
\text { (years) }\end{array}$ & \multicolumn{2}{|l|}{ Male } & \multicolumn{2}{l|}{ Female } & $\begin{array}{l}\text { Total } \\
\text { patients }\end{array}$ & $\begin{array}{c}\text { Cumulative } \\
\text { percentage }\end{array}$ \\
\hline & $n$ & $\%$ & $n$ & $\%$ & & \\
\hline $25-35$ & 9 & 1.18 & 0 & 0.00 & 9 & 1.18 \\
\hline $35-45$ & 16 & 14.55 & 1 & 3.70 & 17 & 12.40 \\
\hline $45-55$ & 33 & 30 & 6 & 22.22 & 39 & 28.46 \\
\hline $55-65$ & 33 & 30 & 13 & 48.15 & 46 & 33.58 \\
\hline $65-75$ & 17 & 15.45 & 7 & 25.92 & 24 & 17.51 \\
\hline $75-86$ & 2 & 1.82 & 0 & 0.00 & 2 & 1.46 \\
\hline Total & 110 & 100 & 27 & 100 & 137 & 100 \\
\hline
\end{tabular}

The age group of 45-65 years recorded more number of overweight and obese patients, with a percentage of $61.73 \%$. Interestingly, there were two patients in the normal weight category in the age group of 55-65 years with OSA as shown in Table 2 and Figure 1.

Table 2: Categorization of the study population by age and body mass index

\begin{tabular}{|l|c|c|c|c|l|l|l|l|}
\hline \multirow{2}{*}{$\begin{array}{l}\text { Age } \\
\text { group } \\
\text { (years) }\end{array}$} & $\begin{array}{l}\text { Normal } \\
\text { weight }\end{array}$ & $\begin{array}{l}\text { Over } \\
\text { weight }\end{array}$ & Obese & $\%$ & Total & $\begin{array}{l}\text { Total } \\
\%\end{array}$ \\
\hline $25-35$ & 0 & 0 & 7 & 5.10 & 2 & 1.45 & 9 & 6.55 \\
\hline $35-45$ & 0 & 0 & 5 & 3.64 & 12 & 8.75 & 17 & 12.39 \\
\hline $45-55$ & 0 & 0 & 14 & 10.2 & 25 & 18.24 & 39 & 28.44 \\
\hline $55-65$ & 2 & 1.45 & 13 & 9.48 & 31 & 22.36 & 46 & 33.29 \\
\hline $65-75$ & 0 & 0 & 6 & 4.37 & 18 & 13.14 & 24 & 17.51 \\
\hline $75-86$ & 0 & 0 & 1 & 0.72 & 1 & 0.72 & 2 & 1.44 \\
\hline Total & 2 & 1.45 & 32 & 33.51 & 93 & 64.66 & 137 & 100 \\
\hline
\end{tabular}

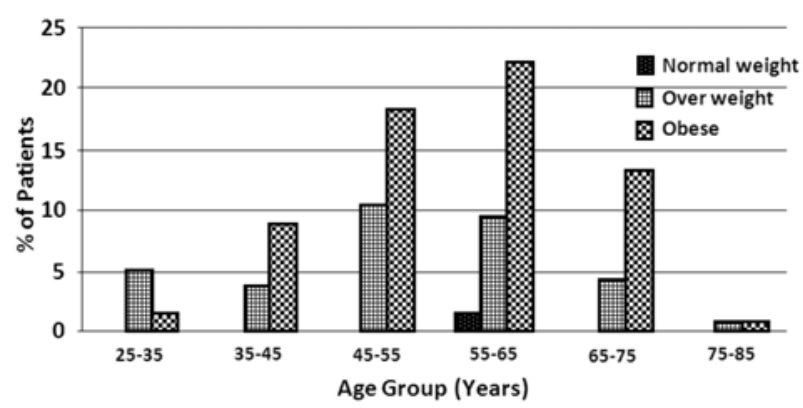

Figure 1: BMI categorization according to age of population

Table 3: Severity of obstructive sleep apnea

\begin{tabular}{|l|l|l|}
\hline Severity & $N$ & Percentage \\
\hline Mild & 13 & 9.48 \\
\hline Moderate & 31 & 22.63 \\
\hline
\end{tabular}

Mild form of OSA was found to be least prevalence with $9.48 \%$ and severe form of OSA in most patients with $67.89 \%$. The details are shown in Table 3 .

The prevalence of all forms of OSA(mild, moderate, and severe)was on a higher side in the age group of 45-65 years, recording $62.05 \%$ as shown in Table 4 and (Figure 2). 
When odds ratio and coefficient of correlation was done for comorbidities with OSA, it was seen that hypertension was closely correlated to OSA. Detailed information is given in (Table 5).

Table 6 and Figure 3 clearly show that patients with hypertension showed the highest percentage of OSA prevalence with a total of 97 patients,and the least was with hypothyroidism, which accounted for only 28 patients.

Table 4: Categorization of obstructive sleep apnea severity with age

\begin{tabular}{|c|c|c|c|c|c|c|c|c|}
\hline \multirow{2}{*}{$\begin{array}{l}\text { Age } \\
\text { group } \\
\text { (years) }\end{array}$} & \multicolumn{6}{|c|}{ Severity } & \multirow[t]{2}{*}{ Total } & \multirow{2}{*}{$\begin{array}{c}\text { Total } \\
\%\end{array}$} \\
\hline & Mild & $\%$ & Moderate & $\%$ & Severe & $\%$ & & \\
\hline $25-35$ & 0 & 0 & 0 & 0 & 9 & 6.57 & 9 & 6.57 \\
\hline $35-45$ & 4 & 2.92 & 2 & 1.45 & 11 & 8.02 & 17 & 12.41 \\
\hline $45-55$ & 4 & 2.92 & 11 & 8.02 & 24 & 17.52 & 39 & 28.47 \\
\hline $55-65$ & 4 & 2.92 & 10 & 7.30 & 32 & 23.36 & 46 & 33.58 \\
\hline $75-86$ & 0 & 0 & 2 & 1.45 & 0 & 0 & 2 & 1.45 \\
\hline Total & 13 & 9.49 & 32 & 23.36 & 93 & 67.88 & 137 & 100 \\
\hline
\end{tabular}

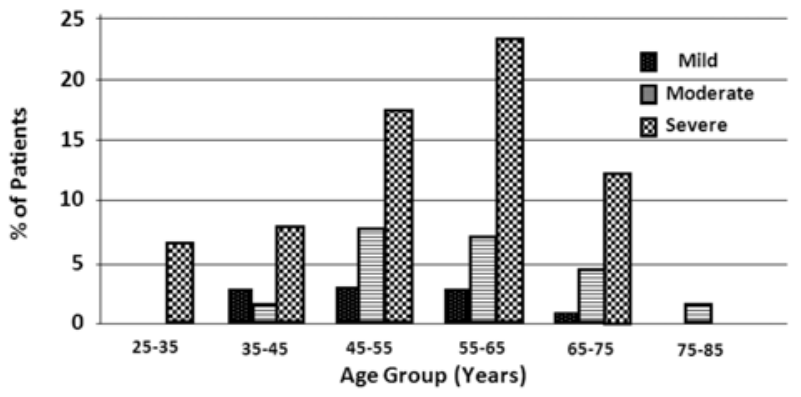

Figure 2: Distribution of severity of OSA according to age

Table 5: Odds ratio and coefficient correlation of comorbidities with OSA

\begin{tabular}{|l|l|l|l|l|}
\hline Comorbidity & $\begin{array}{l}\text { Obstructive } \\
\text { sleep apnea } \\
\text { patients (\%) }\end{array}$ & $\begin{array}{l}\text { Nonobstructive } \\
\text { sleep apnea } \\
\text { patients (\%) }\end{array}$ & $\begin{array}{l}\text { Odds ratio } \\
\text { (confidence } \\
\text { interval) }\end{array}$ & $\begin{array}{l}\text { Coefficient of } \\
\text { correlation }(\boldsymbol{P})\end{array}$ \\
\hline Hypertension & 70.8 & 19.71 & $9.88(5.647,17.284)$ & $0.513(0.01)$ \\
\hline $\begin{array}{l}\text { Diabetes } \\
\text { mellitus }\end{array}$ & 40.15 & 24.09 & $2.11(1.257,3.554)$ & $0.172(0.01)$ \\
\hline Hypothyroidism & 20.44 & 2.92 & $8.54(2.90,25.09)$ & $0.276(0.01)$ \\
\hline $\begin{array}{l}\text { Coronary artery } \\
\text { disease }\end{array}$ & 28.47 & 9.49 & $3.84(1.94,7.52)$ & $0.244(0.01)$ \\
\hline Stroke & 26.28 & 1.46 & $24.05(5.6,102.2)$ & $0.359(0.01)$ \\
\hline
\end{tabular}

Table 6: Categorization of comorbidities based on severity of obstructive sleep apnea

\begin{tabular}{|l|l|l|l|l|l|l|}
\hline Comorbidity & Mild & $\%$ & Moderate & $\%$ & Severe & $\%$ \\
\hline Hypertension & 4 & 2.92 & 25 & 18.25 & 68 & 49.64 \\
\hline Hypothyroidism & 2 & 1.46 & 7 & 5.11 & 19 & 13.87 \\
\hline $\begin{array}{l}\text { Coronary artery } \\
\text { disease }\end{array}$ & 3 & 2.19 & 11 & 8.03 & 25 & 18.25 \\
\hline Stroke & 2 & 1.46 & 8 & 5.84 & 26 & 18.98 \\
\hline
\end{tabular}



Figure 3: Categorization of severity of OSA in different comorbidities

Table 7: Demographic data of patients without comorbidities

\begin{tabular}{|l|l|l|}
\hline & With OSA & \\
\hline & Male & Female \\
\hline Number & 14 & 3 \\
\hline Age (years) & $50.07 \pm 13.42$ & $57.0 \pm 4.36$ \\
\hline BMI $\left(\mathrm{kg} / \mathrm{m}^{2}\right)$ & $31.39 \pm 6.31$ & $30.7 \pm 1.14$ \\
\hline AHI & $45.19 \pm 18.80$ & $19.97 \pm 12.48$ \\
\hline
\end{tabular}

Table 8: The general demographic data of both case and control groups

\begin{tabular}{|l|l|l|}
\hline Parameter & $\begin{array}{l}\text { Case group } \\
(\text { mean } \pm \text { SD })\end{array}$ & $\begin{array}{l}\text { Control group } \\
(\text { mean } \pm \text { SD })\end{array}$ \\
\hline Age (years) & $55.53 \pm 11.374$ & $55 \pm 11.68$ \\
\hline BMI $\left(\mathrm{kg} / \mathrm{m}^{2}\right)$ & $33.02 \pm 5.75$ & $28.07 \pm 5.30$ \\
\hline AHI & $45.50 \pm 24.51$ & - \\
\hline Duration of hypertension (years) & $6.21 \pm 6.82$ & $1.74 \pm 4.43$ \\
\hline Duration of diabetes mellitus (years) & $2.78 \pm 4.91$ & $1.99 \pm 4.71$ \\
\hline Duration of hypothyroidism (years) & $1.00 \pm 2.51$ & $0.13 \pm 0.84$ \\
\hline $\begin{array}{l}\text { Duration of coronary artery disease } \\
\text { (years) }\end{array}$ & $2.17 \pm 4.59$ & $0.87 \pm 3.37$ \\
\hline Event of stroke (years) & $1.80 \pm 3.83$ & $0.04 \pm 0.42$ \\
\hline
\end{tabular}


Table 7 shows the demographics of case group without comorbidities, in which the mean AHI in the men was $45.19 \pm 18.80$ and in women $19.97 \pm 12.48$.

The mean duration of various comorbidities and demographics of case and control groups is shown in (Table 8).

\section{Discussion}

This study shows the ratio of OSA prevalence in men and women as $4: 1$. As seen in the study done by Bixleret al. ${ }^{9}$ where the ratio was found to be $3.3: 1$, it can be interpreted that hormonal influences are also likely to have an important role in pathogenesis of OSA.

It was noted that maximum prevalence of OSA was in middle age group in both men and women as seen in (Table 2). The studies by BaHammamet $a^{10,11}$. have shown that lin 3 middle-aged Saudi male subjects is at risk for OSA and almost 4 of 10 middle-aged Saudi women are at risk for $\mathrm{OSA}^{10,11}$. There is almost 2:1 ratio in the prevalence of increased $\mathrm{BMI}$ in middle age group when compared with lower age group. As the BMI is on the higher side in the middle-aged population, there is greater prevalence of severeOSA in this age group. According to Bixler et al.,the average BMI did increase with age for subjects with OSA ${ }^{12}$. When odds ratio was calculated to check the prevalence of comorbidities in OSA group in comparison with those without OSA, it was found that stroke showed a maximum odds ratio of 26.28 (95\% CI: 5.66, 102.26); but, the width of CI was very high. Hypertension showed an odds ratio of 9.88 (95\% CI: 5.647, 17.28). Hypothyroidism was next with an odds ratio of 8.54 (95\% CI: 2.907, 25.09). Coronary artery disease showed an estimated odds ratio of 3.84 (95\% CI: $1.94,7.58)$. Finally, diabetes revealedan odds ratio of 2.11 (95\% CI: $1.25,3.55)$.

According to the study done by Gonc'alveset $\mathrm{a}^{13}$. OSA was present in 45 patients with OSA $(71 \%)$ and in 4 patients without OSA (38\%). In a logistic regression odel, OSA was strongly and independently associated with resistant hypertension (odds ratio, 4.8; 95\% CI: $2.0,11.7)$. The study results by Mahmood et al. showed the prevalence of type 2 diabetes to be $30.1 \%$ in the group with OSA compared with $18.6 \%$ in those without OSA. The subjects with OSA showed significantly increased odds of type 2 diabetes compared with those without OSA (odds ratio, 1.8, 95\% CI: 1.3, 2.6); but, this association became non significant when subjects without OSAled for confounding variables and covariates (odds ratio, 1.3 , 95\% CI: 0.9, 2.0) $)^{14}$. A study done by Kapur et al. gave an estimate of the risk of OSA in individuals with treated hypothyroidism that was modestly higher (1.47 times) than in individuals who revealedno history of hypothyroidism. The summary odds ratio after stratification for age and gender was $1.47^{15}$. Pekeret $\mathrm{al}^{16}$. conducted a study and created a multiple logistic regression model, and the significant predictors of coronary artery disease incidence were OSA at baseline (odds ratio,4.9; 95\% CI: 1.8, 13.6). In the OSA group, coronary artery disease incidence was observed in 21 of $37(56.8)^{16}$. According to study conducted by Davies et $\mathrm{al}^{17}$. the odds ratio was foundto be 1.44 (95\% CI: 0.88 , $2.41)^{17}$. The patients without comorbidities showed a slightly overweight status, and the AHIwas on a lower side. This shows that, as the weight and obstructive events reduce, there is lower incidence of comorbidities.

\section{Conclusion}

The study showed that prevalence of comorbidities is more in patients with OSA when compared with subjects without OSA. The most correlated comorbidity was found to be hypertension and least was diabetes mellitus.For patients with long-standing hypertension, screening for OSA may be considered. In patients with uncontrolled hypertension even on multiple drugs, referral to a sleep laboratory may be considered to diagnose previously undetected OSA.

\section{Acknowledgements}

We are thankful to Dr. B. Bhaskar Rao, MD and CEO of KIMS, for permitting us to carry out the study and to Mr. Venkat, sleep study technician.

Conflict of Interest: All authors certify that they have no affiliations with or involvement in any organization or entity with any financial interest (such as honoraria; educational grants; participation in speakers' bureaus; membership, employment, consultancies, stock ownership, or other equity interest; and expert testimony or patent-licensing arrangements) or nonfinancial interest (such as personal or professional relationships, affiliations, knowledge, or beliefs) in the subject matter or materials discussed in this manuscript. 


\section{References}

1. Peppard PE, Young T, Palta M, Skatrud J.Prospective study of the association between sleep-disordered breathing and hypertension.N Engl J Med. 2000;342:1378-1384.

2. Nieto FJ, Young TB, LindBK, et al.Association of sleepdisordered breathing, sleep apnea, and hypertension in a large community-based study.JAMA. 2000;283:18291836.

3. Javaheri S, Parker TJ, Wexler L, et al. Occult sleepdisordered breathing in stable congestive heart failure. Ann Intern Med. 1995;122:487-492.

4. Nannapaneni S, Ramar K, Surani S. Effect of obstructive sleep apneaon type 2 diabetes mellitus: a comprehensive literature review. World J Diabetes. 2013;4:238-224.

5. Punjabi NM, Sorkin JD, Katzel LI, Goldberg AP, Schwartz AR, Smith PL. Sleep-disordered breathing and insulin resistance in middle-aged and overweight men. Am J RespirCrit Care Med. 2002;165:677-682.

6. Mayoclinic.org. OSA and cardioembolic stroke risk-Mayo Clinic [Internet].2010.Available from: http:// www.mayoclinic.org/medical-professionals/clinicalupdates/neurosciences/obstructive-sleep-apneacardioembolic-stroke-risk[cited March 20, 2015].

7. Unnikrishnan AG, Menon UV. Thyroid disorders in India: an epidemiological perspective. Indian J Endocrinol Metab.2011;15:S78-S81.

8. American Academy of Sleep Medicine. International Classification of Sleep Disorders: Diagnostic and Coding Manual, 2nd ed. Westchester, IL: American Academy of Sleep Medicine; 2005.

9. Bixler EO, Vgontzas AN, Lin HM, et al. Prevalence of sleepdisordered breathing in women: effects of gender.Am $\mathrm{J}$ RespirCrit Care Med. 2001;163:608-613.
10. BaHammam AS, Alrajeh MS, Al-Jahdali HH, BinSaeed AA. Prevalence of symptoms and risk of sleep apnea in middle-aged Saudi males in primary care. Saudi Med J.2008;29:423-426.

11. Bahammam AS, Al-Rajeh MS, Al-Ibrahim FS, Arafah MA, Sharif MM. Prevalence of symptoms and risk of sleep apnea in middle-aged Saudi women in primary care. Saudi Med J. 2009;30:1572-1576.

12. Bixler EO, Vgontzas AN, TenHave T, Tyson K, Kales A. Effects of age on sleep apnea in men: I. Prevalence and severity.Am J RespirCrit Care Med. 1998;157:144-148.

13. Gonc'alves SC, Martinez D, Gus M, et al. Obstructive sleep apnea and resistant hypertension: a case-control study. Chest.2007;132:1858-1862.

14. Mahmood K, Akhter N, EldeirawiK, et al. Prevalence of type 2 diabetes in patients with obstructive sleep apnea in a multi-ethnic sample. J Clin Sleep Med. 2009;5:215-221.

15. Kapur VK, Koepsell TD, deMaine J, Hert R, Sandblom RE, Psaty BM. Association of hypothyroidism and obstructive sleep apnea. Am J RespirCrit Care Med. 1998;158:13791383.

16. Peker $\mathbf{Y}$, Kraiczi H, Hedner J, Löth S, Johansson $\AA$, Bende $M$. An independent association between obstructive sleep apnoea and coronary artery disease. EurRespir J. $1999 ; 14: 179$.

17. Davies DP, Rodgers H, Walshaw D, James OF, Gibson GJ. Snoring, daytime sleepiness and stroke: a case-control study of first-ever stroke. J Sleep Res. 2003;12:313-318. 